\title{
Surface free energy of enamel treated with sodium hexametaphosphate, calcium and phosphate
}

\author{
José Guilherme Neves ${ }^{\mathrm{a}}$, Marcelle Danelon ${ }^{\mathrm{a}}$, Juliano Pelim Pessan ${ }^{\mathrm{a}}$, Leonardo Raniel Figueiredo ${ }^{\mathrm{a}}$, \\ Emerson Rodrigues Camargo ${ }^{\mathrm{b}}$, Alberto Carlos Botazzo Delbem ${ }^{\mathrm{a}, *}$ \\ ${ }^{a}$ São Paulo State University (Unesp), School of Dentistry, Araçatuba, Department of Pediatric Dentistry and Public Health, Rua José Bonifácio 1193 Araçatuba, SP, Cep \\ 16015-050, Brazil \\ ${ }^{\mathbf{b}}$ Federal University of São Carlos (UFSCar), LIEC-Department of Chemistry, Rodovia Washington Luís, s/n São Carlos, SP, Cep 13565-905, Brazil
}

\section{A R T I C L E I N F O}

\section{Keywords:}

Phosphates

Calcium

Dental enamel

Energy

\begin{abstract}
A B S T R A C T
Objective: This study evaluated the capacity of sodium hexametaphosphate (HMP) at different concentrations to alter the surface properties of dental enamel in order to increase calcium and phosphate adsorption.

Design: Bovine enamel blocks ( $4 \mathrm{~mm} \times 4 \mathrm{~mm}, \mathrm{n}=144,12$ /group) were divided: $0 \%$; $0.25 \%$; $0.5 \%$; and $1 \%$ HMP, followed or not by application of solutions containing $\mathrm{Ca}$ or $\mathrm{Ca}-\mathrm{PO}_{4}$, totaling 12 groups. The treatments were performed for $2 \mathrm{~min}$, and the surface free energy $(\mathrm{mN} / \mathrm{m})$ was calculated by measuring the contact angles of three probing liquids (deionized water, diiodomethane and ethylene glycol), which was used to determine the polar and nonpolar components of the enamel surface. Calcium $(\mathrm{Ca})$, phosphate $\left(\mathrm{PO}_{4}\right)$ and $\mathrm{HMP}$ in the solutions treatment solutions were analyzed before and after treatment. The data presented normal and homogeneous distribution and then were subjected to ANOVA, followed by Student-Newman Keuls' test ( $\mathrm{p}<0.05$ ).

Results: The higher the \% of HMP in the solutions, the greater HMP adsorption and more electron-donor sites on enamel surface were achieved ( $\mathrm{p}<0.05$ ). Also, Ca adsorption was higher with increasing\% HMP in the solutions $(\mathrm{p}<0.05)$, which in turn reduced electron-donor sites on enamel surface. Increased $\mathrm{Ca}$ and $\mathrm{PO}_{4}$ adsorption occurred at $0.5 \%$ and $1 \% \mathrm{HMP}$ after treatment with $\mathrm{Ca}-\mathrm{PO}_{4}$ solution, resulting in a less electron-donor sites on surface when compared to the other treatments $(\mathrm{P}<0.05)$.

Conclusions: HMP leads to a more electron-donor sites on enamel surface, what promotes greater adsorption of $\mathrm{Ca}$ and $\mathrm{PO}_{4}$ ions.
\end{abstract}

\section{Introduction}

As dental caries is the most common chronic oral disease worldwide (Clarkson, Watt, \& Rugg-Gunn, 2010), enhancing the ability of fluoridated products against mineral loss can potentially improve its effect against dental caries. Sodium hexametaphosphate (HMP) is a cyclic inorganic phosphate (Kulaev, Vagabov, \& Kulakovskaya, 2005, Ch. 1) that has been added to fluoride products as toothpastes (Camara, Miyasaki, Danelon, Sassaki, \& Delbem, 2014; Camara et al., 2015, 2016) and gels (Conceição et al., 2015) with the purpose to increase the capacity of such products to reduce enamel demineralization and to enhance remineralization. The assumption would be that HMP would retain ionic species like $\mathrm{CaF}^{+}$and $\mathrm{Ca}^{2+}$, leading to a reticular formation of HMP-Ca ${ }^{2+}$ layer on enamel, which in turn increases calcium availability during de- and re-mineralization processes (Camara et al., 2014, 2015, 2016; Conceição et al., 2015). However, the above-mentioned hypothesis still needs to be scientifically proven, given that both
HMP and tooth enamel are negatively charged (Choi, Wen, \& Smith, 1993). Thus, the study of the interactions and chemical bonds among HMP, the enamel surface and a calcium and phosphate-rich medium might help to better understand the mechanisms surrounding the effects of HMP on enamel de- and remineralization.

Surface reactivity is assessed by surface free energy (SFE) (O'Brien, 2002, Ch. 5; Tsujimoto et al., 2016), which can be measured by determining the contact angles formed by different probing liquids on a solid surface (Neumann, Good, Hope, \& Seipal, 1974; Owens \& Wendt, 1969). Among the different methods to determine these parameters, the approach described by Van Oss, Fowkes and Good, and Chaudhury (Neumann et al., 1974; Owens \& Wendt, 1969) allows the calculation of the dispersion values, acid-base Lewis parts, polar force and hydrogen bond force, which determine the Lifshitz-van der Waals acid-base equation (Chaudhury, 1996; Good, 1992). Although the acid-base components of surface free energy of some polymeric surfaces, such as polyvinyl chloride (PVC), can exhibit some anomalies when calculated

\footnotetext{
* Corresponding author.

E-mail addresses: adelbem@foa.unesp.br, adelbem@pq.cnpq.br (A.C.B. Delbem).
} 
by this method, (Della Volpe \& Siboni, 1997), several researchers employed it to estimate the SFE on the surface of enamel (Imai et al., 2017). This method has the same foundation of hydrophobicity angle measurement, despite hydrophobicity is measured only by angles made with water. Therefore, the use of other probing liquids (with different physicochemical properties) (Carlen, Nikdel, Wennerberg, Holmberg, \& Olsson, 2001; Sipahi, Anil, \& Bayramli, 2001) in addition to water can provide further information on the interactions between treatment solutions and a given surface.

Thus, the aim of this study was to analyze the capacity of HMP to adsorb on enamel, as well as to determine enamel SFE after treatment with different concentrations of HMP, followed or not by the application of solutions containing calcium or calcium-phosphate. The null hypothesis was that HMP does not alter enamel SFE and does not influence calcium and phosphate adsorption on enamel.

\section{Material and methods}

\subsection{Experimental design}

Enamel blocks $(4 \times 4 \times 4 \mathrm{~mm}, \mathrm{n}=144)$ obtained from buccalcervical region of bovine incisors were stored in $2 \%$ formaldehyde solution for 30 days. The teeth were extracted from $\sim 3$ year old bovine and same race. The enamel surface of the blocks was sequentially polished using water-cooled silicon carbide paper disks $(600,800$, and 1200 grit, Extec, Enfield, CT, USA) with a final polish using a felt disk (Extec) in a grinding polisher (VECTOR-PHOENIX BETA, Buehler, Lake Bluff, Il, USA). At the end of each polisher disk, the blocks were cleaned by ultrasound in deionized water (Unique USC 1400, Indaiatuba, SP, Brazil) during $20 \mathrm{~min}$ at room temperature. As inclusion criteria, blocks should be flat, with no risks, cracks or hypoplasia. They were divided into twelve groups ( $n=12$ /group), according to the following treatment solutions: HMP at 0, 0.25, 0.5 and 1\% HMP, followed or not by immersion in a solutions containing calcium $(1.25 \mathrm{mmol} / \mathrm{L} \mathrm{Ca})$, or calcium and phosphate $(1.25 \mathrm{mmol} / \mathrm{L} \mathrm{Ca}$ and $3.5 \mathrm{mmol} / \mathrm{L} \mathrm{P})$. Surface free energy analysis was performed by determining the contact angles of three probing liquids on enamel surface. Calcium and phosphorus concentrations in the treatment solutions were determined before and after the treatments.

\subsection{Formulation of the solutions and treatment}

Solutions were prepared using HMP (CAS 68915-31-1, Aldrich Chemistry, UK), at concentrations of $0,0.25,0.5$ and $1 \%$ (Camara et al., 2014, 2015). Solutions containing calcium $\left(1.25 \mathrm{mmol} / \mathrm{L} \mathrm{CaCl}{ }_{2} \cdot 2 \mathrm{H}_{2} \mathrm{O}\right)$ and $\mathrm{Ca}$ and $\mathrm{PO}_{4} \quad\left(1.25 \mathrm{mmol} / \mathrm{L} \quad \mathrm{CaCl}_{2} \cdot 2 \mathrm{H}_{2} \mathrm{O}\right.$ and $3.5 \mathrm{mmol} / \mathrm{L}$ $\mathrm{NaH}_{2} \mathrm{PO}_{4} \cdot 2 \mathrm{H}_{2} \mathrm{O}$; Sigma, USA) were also prepared according to average values from human saliva (Edgar, Dawes, \& O'Mullane, 2012, Ch. 5). Blocks ( $\mathrm{n}=36 /$ group) were immersed in individual flasks containing $1 \mathrm{~mL}$ of HMP solutions under constant agitation (shaker table TE-420 Orbital Tecnal, Brazil) over a period of $2 \mathrm{~min}$. Following, blocks were gently washed in deionized water for $30 \mathrm{~s}$ and air dried. Twelve blocks of each group were stored for posterior analysis, while the remaining specimens were immersed in individual flasks containing $1 \mathrm{~mL}$ of a Ca solution (12 blocks/group) or in a Ca- $\mathrm{PO}_{4}$ solution (12 blocks/group), under constant agitation for $1 \mathrm{~min}$.

\subsection{Calcium and phosphorus analysis}

Ca analysis was performed spectrophotometrically (Microplate Spectrophotometer EON, Biotek, USA), using the Arsenazo III method, at wavelength of $650 \mathrm{~nm}$ (Vogel, Chow, \& Brow, 1983). Aliquots of $5 \mu \mathrm{L}$ were taken from the samples and added to $50 \mu \mathrm{L}$ of deionized water and $50 \mu \mathrm{L}$ of Arsenazo. For calibration, standards containing $40-200 \mu \mathrm{g} \mathrm{Ca} /$ $\mathrm{mL}$ were used. Phosphorus was determined by the molybdate method, using aliquots of $20 \mu \mathrm{L}$ of the solutions, added to a mixture of $50 \mu \mathrm{L}$ molybdate and $20 \mu \mathrm{L}$ reactive reducer, as described by Fiske and Subbarow (1925). These analyses were performed before and after the treatments, and the adsorption to enamel calculated by subtracting the final concentrations from the initial values $(\Delta, \mu \mathrm{g})$. Phosphorus of the HMP solutions was determined after acid hydrolysis. Aliquots of $0.2 \mathrm{~mL}$ of the HMP solutions were added of $0.2 \mathrm{~mL}$ of hydrochloric acid $(\mathrm{HCl})$ $1.0 \mathrm{~mol} / \mathrm{L}$ and heated in water at $100{ }^{\circ} \mathrm{C}$ for $1 \mathrm{~h}$ (Tiveron, Delbem, Gaban, Sassaki, \& Pedrini, 2013). The resulting solutions were then analyzed as described above.

\subsection{SFE measurements}

The physicochemical properties of the enamel surface were characterized by contact angle measurements, using the sessile drop method to determine the surface free energy. Measurements were performed by an automatic goniometer (DSA 100S, Krüss, Hamburg, Germany) using three probing liquids: diiodomethane, water and ethylene glycol. The treated blocks were air dried for $45 \mathrm{~min}$ in order to stabilize the pellicle formed (van der Mei et al., 2002). After, $0.5 \mu \mathrm{L}$ of each liquid was automatically dispensed on a different quadrant of enamel surface of each block utilizing glass syringe $(500 \mu \mathrm{L})$ and needle of $0.5 \mathrm{~mm}$ gage. Counted $1 \mathrm{~s}$, the contact angles (right and left) were measured using the images captured by a CCD camera and Tangent method (Drop Shape Analysis DSA4 Software, version 2.0-01, Krüss). Each drop was measured 5-fold during $5 \mathrm{~s}$ at $20^{\circ} \mathrm{C}$ (van der Mei et al., 2002) and relative humidity of $44 \% \pm 6$. Different parameters, such as acid $\left(\gamma^{+}\right.$, receptor component), base $\left(\gamma^{-}\right.$, donor component) and Lifshiz van der Waals $\left(\gamma^{\mathrm{LW}}\right.$, nonpolar component) of surface free energy $(\mathrm{mN} / \mathrm{m})$ were calculated according to the model of van Oss, Chaudhery and Good for the determination of the substrates free energy (Della Volpe \& Siboni, 1997; Vogler, 1998).

\subsection{Statistical analysis}

The values of contact angle, SFE parameters, $\mathrm{HMP}, \mathrm{Ca}$ and $\mathrm{PO}_{4}$ adsorbed to enamel were considered as outcome measures and the $\%$ of HMP and post treatment $\mathrm{Ca}$ and $\mathrm{Ca}-\mathrm{PO}_{4}$ solutions, as the variation factors. The data presented normal (Kolmogorov-Smirnov) and homogeneous (Cochran) distributions and were submitted to two-way analysis of variance followed by Student-Newman-Keuls' test for multiple comparisons. Analyses were performed using the Sigma Plot statistical software (version 12.0, Systat Software Inc., San Jose, CA, USA) with a significance level set at $5 \%$.

\section{Results}

Treatment with HMP led to lower values of contact angles for the three probing liquids $(\mathrm{p}<0.001)$ compared to HMP-free solutions (Table 1). Surface free energy $\left(\gamma_{\mathrm{s}}\right)$ was only significantly higher with $0.25 \% \operatorname{HMP}(p=0.002)$. The values of apolar component $\left(\gamma_{\mathrm{S}}^{\mathrm{LW}}\right)$ from enamel surface were higher after treatment with $\operatorname{HMP}(\mathrm{p}=0.001)$. The values of polar component $\left(\gamma_{\mathrm{S}}^{\mathrm{AB}}=\right.$ Lewis acid-base) became more negative with increasing\% of HMP $(p=0.017)$ (Fig. 1). Among the parameters from $\gamma_{\mathrm{S}}{ }^{\mathrm{AB}}, \gamma_{\mathrm{S}}{ }^{+}=$eletron-acceptor (Lewis acid) and $\gamma_{\mathrm{S}}{ }^{-}=$eletron-donor (Lewis base), higher $\gamma_{\mathrm{S}}{ }^{-}$values were observed with increasing\% of HMP ( $p<0.001$ ). The same was observed for HMP adsorption to enamel ( $\mathrm{p}<0.001$ ) (Fig. 2A). Significant correlations were observed between HMP adsorption and $\gamma_{\mathrm{s}}{ }^{\mathrm{AB}}$ (Pearson's $\mathrm{r}=0.600 ; \mathrm{p}<0.001$ ) and $\gamma_{\mathrm{s}}{ }^{-}$(Pearson's $\mathrm{r}=-0.736 ; \mathrm{p}<0.001$ ).

Enamel surface treated with the Ca solution only (i.e. not pretreated with HMP) presented higher values of contact angles for the three probing liquids $(p<0.005)$, as well as a reduction of $\gamma_{s}$ values ( $\mathrm{p}=0.013$ ) when compared to enamel without any treatment (Table 1). Furthermore, not alteration of the $\gamma_{\mathrm{S}}{ }^{\mathrm{AB}}, \gamma_{\mathrm{S}}{ }^{+}$and $\gamma_{\mathrm{S}}{ }^{-}$values $(p=0.119)$ and a slight reduction of $\gamma_{S}{ }^{\mathrm{LW}}$ values $(\mathrm{p}=0.002)$ were observed (Fig. 1). Treatment with Ca of enamel pretreated with HMP 
Table 1

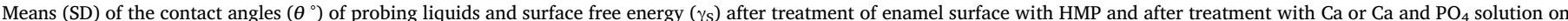
enamel surface pretreated with HMP solutions $(\mathrm{n}=12)$.

\begin{tabular}{|c|c|c|c|c|c|}
\hline Treatments & & Water $\theta\left(^{\circ}\right)$ & Diiodomethane $\theta\left(^{\circ}\right)$ & Ethylene glycol $\theta\left(^{\circ}\right)$ & $\gamma_{\mathrm{s}}(\mathrm{mN} / \mathrm{m})$ \\
\hline \multirow[t]{4}{*}{ no-Ca and $\mathrm{PO}_{4}$} & 0\%HMP & $67.7^{\mathrm{a}}(4.1)$ & $52.4^{\mathrm{a}}(5.5)$ & $55.4^{\mathrm{a}^{*}}(4.2)$ & $28.8^{\mathrm{a}}(4.6)$ \\
\hline & $0.25 \% \mathrm{HMP}$ & $48.0^{\mathrm{b}}(4.4)$ & $39.0^{\mathrm{b}}(5.1)$ & $37.5^{\mathrm{b}}(5.7)$ & $33.6^{\mathrm{b}^{*}}(3.2)$ \\
\hline & $0.5 \% \mathrm{HMP}$ & $43.1^{\mathrm{c}}(3.8)$ & $48.0^{c^{*}}(6.4)$ & $40.8^{\mathrm{b}}(4.3)$ & $27.5^{\mathrm{a}}(3.9)$ \\
\hline & 1\%HMP & $40.3^{\mathrm{c}}(8.6)$ & $43.6^{\mathrm{d}}(5.4)$ & $40.8^{\mathrm{b}}(5.1)$ & $25.9^{\mathrm{a}^{*}}(5.2)$ \\
\hline \multirow[t]{4}{*}{$\mathrm{Ca}$} & 0\%НMP & $73.6^{\mathrm{a}}(6.3)$ & $57.6^{\mathrm{a}^{\mathrm{k}}}(2.6)$ & $62.1^{\mathrm{a}}(3.7)$ & $25.3^{\mathrm{a}^{*}}(2.3)$ \\
\hline & $0.25 \% \mathrm{HMP}$ & $68.5^{\mathrm{a}^{*}}(6.0)$ & $55.8^{\mathrm{a}^{* *}}(3.9)$ & $53.4^{\mathrm{b}^{*}}(2.9)$ & $31.5^{\mathrm{b}^{*}}(3.4)$ \\
\hline & $0.5 \% \mathrm{HMP}$ & $63.7^{\mathrm{b}}(5.6)$ & $50.7^{\mathrm{b}^{*}}(3.4)$ & $49.7^{\mathrm{c}}(4.3)$ & $31.7^{\mathrm{b}^{*}}(3.4)$ \\
\hline & 1\%HMP & $69.4^{\mathrm{a}^{\mathrm{*}}}(6.2)$ & $54.2^{\mathrm{a}^{\mathrm{k}}}(3.5)$ & $58.5^{\mathrm{d}}(3.5)$ & $26.5^{\mathrm{a}^{*}}(2.9)$ \\
\hline \multirow{4}{*}{ Ca-PO ${ }_{4}$} & 0\%НMP & $58.4^{\mathrm{a}}(3.1)$ & $58.3^{\mathrm{a}^{\mathrm{k}}}(2.8)$ & $54.7^{\mathrm{a}^{* *}}(3.2)$ & $24.0^{\mathrm{a}^{*}}(4.2)$ \\
\hline & $0.25 \% \mathrm{HMP}$ & $64.8^{\mathrm{b}^{*}}(2.2)$ & $55.0^{\mathrm{a}, \mathrm{b}^{\mathrm{k}}}(2.3)$ & $54.4^{\mathrm{a}^{*}}(2.5)$ & $27.3^{\mathrm{b}}(3.4)$ \\
\hline & $0.5 \% \mathrm{HMP}$ & $68.8^{\mathrm{b}, \mathrm{c}}(3.1)$ & $56.7^{\mathrm{a}, \mathrm{b}}(3.1)$ & $53.8^{\mathrm{a}}(3.3)$ & $31.0^{c^{*}}(3.0)$ \\
\hline & 1\%HMP & $70.4^{\mathrm{c}^{\star *}}(3.7)$ & $53.4^{\mathrm{b}^{\mathrm{k}}}(2.4)$ & $52.2^{\mathrm{a}}(3.1)$ & $33.2^{\mathrm{c}}(2.3)$ \\
\hline
\end{tabular}

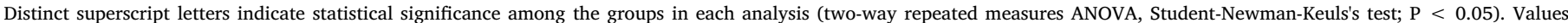
between parentheses indicate the standard deviation of the mean. Asterisk means there is no significant difference between groups with the same\% HMP.

led to higher contact angles for the three probing liquids compared to enamel without Ca treatment. Also, $\gamma_{S}$ values were higher for enamels treated with $0.25 \%$ and $0.5 \%$ of HMP ( $\mathrm{p}=0.002)$. Ca treatment led to less negative $\gamma_{\mathrm{S}}^{\mathrm{AB}}$ values according to HMP content in the treatment solutions, and a reduction of $57 \%$ for $\gamma_{\mathrm{S}}{ }^{-}$values (Fig. 1B) for all\% of HMP $(\mathrm{p}<0.001)$. In addition, $\gamma_{\mathrm{S}}{ }^{\mathrm{LW}}$ values after treatment with Ca were significantly lower (Fig. 1A) in relation to its counterpart without Ca treatment $(\mathrm{p}=0.013)$.
Treatment with $\mathrm{Ca}-\mathrm{PO}_{4}$ solution of enamel pretreated with HMP promoted higher contact angles for the three probing liquids compared to enamel treated with HMP only (Table 1 ). The $\gamma_{\mathrm{S}}$ values were higher for enamel treated with $0.5 \%$ and $1 \%$ of HMP $(\mathrm{p}=0.002)$. In addition, higher adsorption of HMP on enamel increased the absorption of $\mathrm{Ca}$ and $\mathrm{PO}_{4}$ after treatment with $\mathrm{Ca}-\mathrm{PO}_{4}$ solution (Fig. 2B). A dose-response relationship between adsorption of HMP and Ca (Pearson's $\mathrm{r}=0.601$; $\mathrm{p}<0.001$ ) and $\mathrm{PO}_{4}$ (Pearson's $\mathrm{r}=0.622 ; \mathrm{p}<0.001$ ) adsorption on

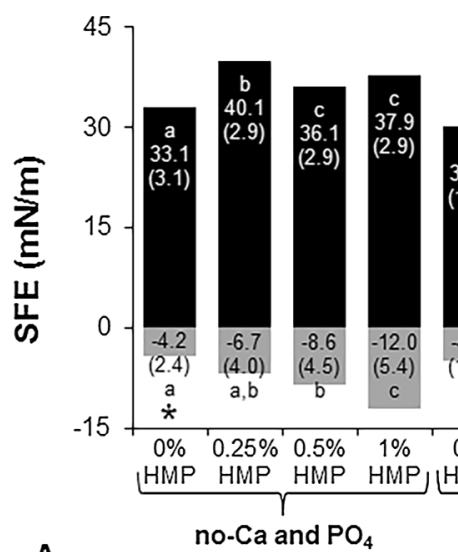

A

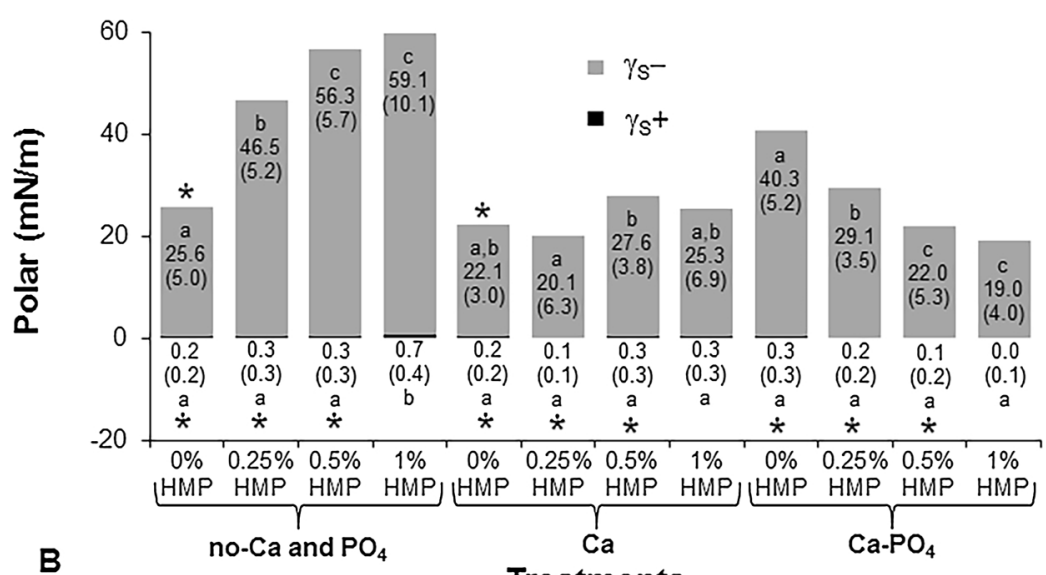

Treatments
- $\gamma_{S}{ }^{L W} \quad \gamma_{S}^{A B}$

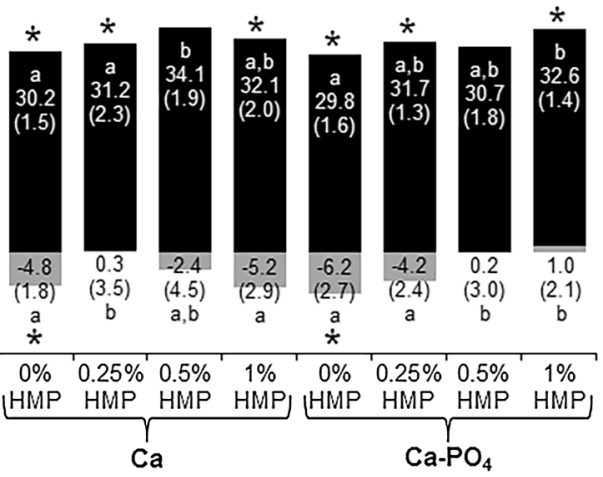

Treatments

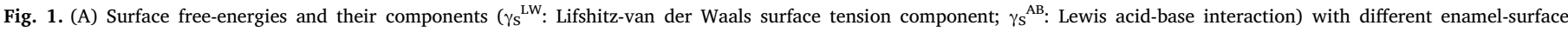

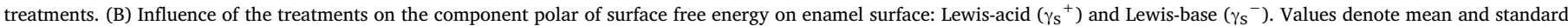

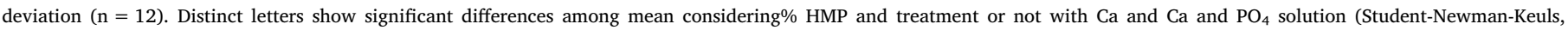
$\mathrm{p}<0.05$ ). Asterisk means there is no significant difference between groups with the same $\%$ HMP. 

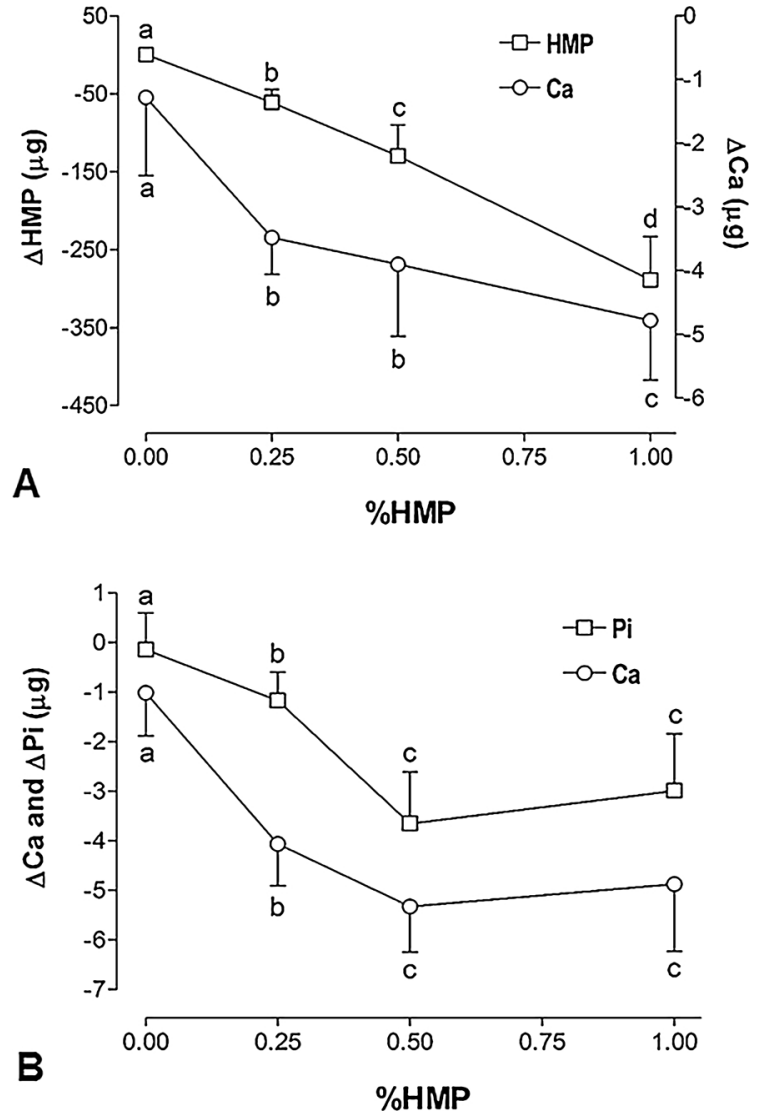

Fig. 2. Mean (SD) of HMP adsorbed (A) on enamel surface after treatment with different $\%$ of HMP solutions. Ca adsorbed (A) on enamel pretreated with different concentration of HMP after treatment with Ca solution. (B) Ca and Pi adsorbed on enamel pretreated with different concentration of HMP after treatment with solution containing $\mathrm{Ca}$ and $\mathrm{PO}_{4}$. Distinct letters show significant differences between the \% HMP for each adsorption analysis (Student-Newman-Keuls, $\mathrm{p}<0.05$ ).

enamel was observed. Furthermore, $\gamma_{S}{ }^{\mathrm{AB}}$ values became positive with increasing $\mathrm{Ca}$ (Pearson's $\mathrm{r}=-0.637$ ) and $\mathrm{PO}_{4}$ (Pearson's $\mathrm{r}=-0.621$ ) adsorption on enamel. Also, $\gamma_{\mathrm{s}}{ }^{-}$values decreased $(\mathrm{p}<0.002)$, showing a significant correlation with $\mathrm{Ca}$ (Pearson's $\mathrm{r}=0.759$; $\mathrm{p}<0.001$ ) and $\mathrm{PO}_{4}$ (Pearson's $\mathrm{r}=0.712 ; \mathrm{p}<0.001$ ) adsorption on enamel.

\section{Discussion}

This study evaluated effect of HMP, followed or not by treatment with calcium or calcium/phosphate solutions, on the SFE of enamel. The results showed that the adsorption of HMP on enamel enhanced the adsorption of calcium and phosphate, so that the null hypothesis was rejected. A dose-response relationship was observed between the amount of HMP in the solutions and variables of adsorption, polar component $\left(\gamma_{\mathrm{S}}{ }^{\mathrm{AB}}=\right.$ Lewis acid-base) and $\gamma_{\mathrm{S}}{ }^{-}$(Lewis base eletrondonor).

Considering only the contact angle with water $\left(\theta_{\mathrm{W}}\right)$, it is possible to affirm that the treatment with HMP increases the hydrophilic character of enamel surface (Table 1), which makes it more liable to wetting, given that the contact angles were lower than $65^{\circ}$ (Rüterman et al., 2011; van der Mei, White, \& Busscher, 2004). Enamel not treated with HMP showed a hydrophobic characteristic and a lower probability of bacterial adhesion in as much as $\gamma_{\mathrm{s}}<30 \mathrm{mN} / \mathrm{m}$ (Knorr, Combe, Wolff, \& Hodges, 2005; van Oss, 1993) and $\gamma_{\mathrm{S}}{ }^{+}$close to zero, as well as $\gamma_{\mathrm{s}}{ }^{-}$is less than $28.5 \mathrm{mN} / \mathrm{m}$ (van Oss, 1995). The adsorptions of HMP on enamel, on the other hand, occur leaving the surface with larger eletrondonor site (Fig. 1B). Despite $\gamma_{\mathrm{S}}{ }^{-}$values higher than $28.5 \mathrm{mN} / \mathrm{m}$ (what characterizes a hydrophilic surface) (Olsson, van der Heijde, \& Holmberg, 1992; van Oss, 1995), the $\gamma_{S}$ remained unaltered because a negative $\gamma_{S}{ }^{A B}$ were higher and positive $\gamma_{S}{ }^{L W}$ values due the HMP adsorption (Fig. 1A). The increase of $\gamma_{S}{ }^{\mathrm{LW}}$ values indicates hydrogen bonds between hydroxyl groups from enamel surface and phosphate groups from HMP. Although $\gamma_{S}$ could suggest a hydrophobic surface, data from $\theta_{\mathrm{W}}, \gamma_{\mathrm{S}}{ }^{\mathrm{LW}}$ and $\gamma_{\mathrm{S}}{ }^{\mathrm{AB}}\left(\gamma_{\mathrm{S}}{ }^{+} ; \gamma_{\mathrm{S}}{ }^{-}\right)$effectively indicate a hydrophilic surface (Harnett, Alderman, \& Wood, 2007; Quirynen \& Bollen, 1995). However, the treatment with $\mathrm{Ca}$ and $\mathrm{Ca}-\mathrm{PO}_{4}$ solutions led to a more hydrophobic enamel surface when pre-treated with HMP (Table 1), since the $\theta_{\mathrm{W}}$ values (Rüterman et al., 2011) and the $\gamma_{\mathrm{S}}$ values were close to $30 \mathrm{mN} / \mathrm{m}$, and $\gamma_{\mathrm{s}}{ }^{-}$values (Fig. 1B) were less than $28.5 \mathrm{mN} / \mathrm{m}$ (Knorr et al., 2005; van Oss, 1993; van Oss, 1995).

As the enamel surface became with larger amount of electron-donor sites due to adsorption of HMP, the adsorption of calcium on enamel was enhanced in the same ratio as the $\gamma_{\mathrm{s}}{ }^{-}$parameter increases (Figs. 2A and 1B). Negative surfaces can be partly or entirely neutralized by plurivalent cations leading to a hydrophobic surface (Olsson et al., 1992). Apolar and polar components of the surface free energy were lower and close to enamel prior to treatment with HMP, which explains the previous studies about the reduction of enamel demineralization due the adsorption of HMP and its bond to calcium on enamel surface (Camara et al., 2014, 2015, 2016; Conceição et al., 2015). Enamel without treatment with HMP adsorbed around $200 \%$ less calcium that surfaces treated with HMP (Fig. 2A). This indicates no binding to phosphate ions on the hydroxyapatite surface (Harding, Rashid, \& Hing, 2005; Vandiver, Dean, Patel, Bonfield, \& Ortiz, 2005), since the values of polar component $\left(\gamma_{S}{ }^{\mathrm{AB}}\right)$ and its parameters $\left(\gamma_{\mathrm{S}}{ }^{+} ; \gamma_{\mathrm{S}}{ }^{-}\right)$did not change. The adsorption of calcium without changing the surface charge probably occurred by a displacement of two surfaces $\mathrm{H}^{+}$ions by a $\mathrm{Ca}^{2+}$ ion (Harding et al., 2005). Nevertheless, the surface became more hydrophobic because of higher $\theta_{\mathrm{W}}$ and lower $\gamma_{\mathrm{S}}$ (as consequence of $\gamma_{\mathrm{S}}{ }^{\mathrm{LW}}$ ) when compared to enamel prior to HMP or calcium. Thus, the formation of HMP layer covering the enamel provides more phosphate sites, thus increasing calcium retention. As consequence, a supersaturation of these ions close to the surface occurs, leading to a surface more prone to adsorption of phosphates ions. These data show the formation of HMPCa layer, therefore proving the hypotheses of previous studies (Camara et al., 2014, 2015, 2016; Conceição et al., 2015) that explain the effect of HMP on reducing mineral loss in the enamel.

The treatment of the enamel surface with calcium and phosphate solutions (not pretreated with HMP) turned the surface hydrophilic considering the $\theta_{\mathrm{W}}<65^{\circ}$ and $\gamma_{\mathrm{S}}{ }^{-}>28.5 \mathrm{mN} / \mathrm{m}$, even reducing $\gamma_{\mathrm{s}}$ and $\gamma_{\mathrm{S}}{ }^{\mathrm{LW}}$ values. As the calcium phosphate solution has the possibility to form ionic species with different charges and activities, enamel reactivity depends of the electrical charge created on the enamel surface. Utilizing the PHREEQC Interactive speciation software (version 2.18.3.5570) to calculate these species, it was possible to arrange in a descending order of reactivity, from $\mathrm{H}_{2} \mathrm{PO}_{4}{ }^{-}>\mathrm{Ca}^{2+}>\mathrm{HPO}_{4}{ }^{2-}>\mathrm{CaH}_{2} \mathrm{PO}_{4}{ }^{+}$at $37^{\circ} \mathrm{C}$, at pH 5.92, and density of $1.0 \mathrm{~g} / \mathrm{cm}^{3}$. The adsorption of $\mathrm{Ca}^{2+}$ and $\mathrm{HPO}_{4}{ }^{2-}$ seems to explain the increase of the electron-donor sites $\left(\gamma_{\mathrm{s}}{ }^{-}=40.3 \mathrm{mN} / \mathrm{m}\right)$ on enamel surface prior to HMP faced with lower adsorption values (Fig. 1B). As the enamel surface present more electron-donor sites after the treatment with HMP, the reactivity with $\mathrm{Ca}^{2+}$ is greater leading to more adsorption of $\mathrm{H}_{2} \mathrm{PO}_{4}{ }^{-}$and $\mathrm{CaH}_{2} \mathrm{PO}_{4}{ }^{+}$, resulting in lower $\gamma_{\mathrm{S}}^{\mathrm{AB}}$ values and reduction in the $\gamma_{\mathrm{S}}{ }^{-}$parameter (Fig. 1). Also, the calcium and phosphate ions will be on the HMP-layer and not on enamel surface, maintaining the pores open and facilitating ions diffusion into the enamel (Camara et al., 2014). These differences might explain the higher ability to reduce the demineralization or enhance the remineralization of enamel adding HMP oral health products (Camara et al., 2014, 2015, 2016; Conceição et al., 2015). These data are in line with results of an in situ study (Camara et al., 2016) that showed a higher calcium concentration in enamel in the presence of HMP. Also, it showed the importance of ionic species as $\mathrm{Ca}^{2+}, \mathrm{H}_{2} \mathrm{PO}_{4}{ }^{-}$and $\mathrm{CaH}_{2} \mathrm{PO}_{4}{ }^{+}$ during de-remineralization process. Although it was possible to determine the influence of HMP on the adsorption of important ions in the process of 
de-remineralization of enamel, the role played by fluoride in a such system has not yet been determined.

It was concluded that the adsorption of HMP on enamel increased the adsorption of calcium and phosphate. The polar component $\left(\gamma_{\mathrm{S}}{ }^{\mathrm{AB}}\right)$ of the surface free energy and its $\gamma_{\mathrm{s}}{ }^{-}$parameter from the enamel surface were higher with the HMP treatment.

\section{Funding}

This study was supported by CNPq (National Council for Scientific and Technological Development, grant 308981/2014-6), CAPES (Coordination for the Improvement of Higher Education Personnel, scholarship to the first author), and FAPESP (The São Paulo Research Foundation, grant 2015/20829-5) for the concession of a scholarship to the third author.

\section{Conflicts of interest}

None.

\section{Ethical approval}

This study did not involve experiments with animals or humans, so that no Ethical Approval was needed.

\section{Acknowledgments}

The authors are grateful to CNPq, CAPES and FAPESP by financial support.

\section{References}

Camara, D. M., Miyasaki, M. L., Danelon, M., Sassaki, K. T., \& Delbem, A. C. (2014). Effect of low-fluoride toothpastes combined with hexametaphosphate on in vitro enamel demineralization. Journal of Dentistry, 42, 256-262.

Camara, D. M., Pessan, J. P., Francati, T. M., Santos Souza, J. A., Danelon, M., \& Delbem, A. C. (2015). Synergistic effect of fluoride and sodium hexametaphosphate in toothpaste on enamel demineralization in situ. Journal of Dentistry, 43, 1249-1254.

Camara, D. M., Pessan, J. P., Francati, T. M., Souza, J. A. S., Danelon, M., \& Delbem, A. C. (2016). Fluoride toothpaste supplemented with sodium hexametaphosphate reduces enamel demineralization in vitro. Clinical Oral Investigation, 20, 1981-1985.

Carlen, A., Nikdel, K., Wennerberg, A., Holmberg, K., \& Olsson, J. (2001). Surface characteristics and in vitro biofilm formation on glass ionomer and composite resin. Biomaterials, 22, 48-487.

Chaudhury, M. K. (1996). Interfacial interaction between low energy surfaces. Materials Science \& Engineering $R, 16,97-159$.

Choi, I. K., Wen, W. W., \& Smith, R. W. (1993). Technical note the effect of a long chain phosphate on the adsorption of colectors on kaolinite. Minerals Engineering, 6, 1191-1197.

Clarkson, J., Watt, R. G., \& Rugg-Gunn, A. J. (2010). Proceedings, 9th world congress on preventive dentistry (WCPD): Community participation and global alliances for lifelong oral health for all, Phuket, Thailand. Advance Dental Research, 22, 2-30.

Conceição, J. M., Delbem, A. C., Danelon, M., Camara, D. M., Wiegand, A., \& Pessan, J. P. (2015). Fluoride gel supplemented with sodium hexametaphosphate reduces enamel erosive wear in situ. Journal of Dentistry, 43, 1255-1260.

Della Volpe, C., \& Siboni, S. (1997). Some reflections on acid-base solid surface free energy theories. Journal of Colloid and Interface Science, 195, 121-136.

Edgar, M., Dawes, C., \& O'Mullane, D. (2012). Saliva and oral healthBritish dental journal (4th ed.). .

Fiske, C. H., \& Subbarow, Y. (1925). The colorimetric determination of phosphorus. Journal of Biological Chemistry, 66, 375-400.

Good, R. J. (1992). Contact angle, wetting, and adhesion: A critical review. Journal of Adhesion Science and Technology, 6, 1269-1302.

Harding, I. S., Rashid, N., \& Hing, K. A. (2005). Surface charge and the effect of excess calcium ions on the hydroxyapatite surface. Biomaterials, 26, 6818-6826.

Harnett, E. M., Alderman, J., \& Wood, T. (2007). The surface energy of various biomaterials coated with adhesion molecules used in cell culture. Colloids Surface B: Biointerfaces, 55, 90-97.

Imai, A., Takamizawa, T., Sai, K., Tsujimoto, A., Nojiri, K., Endo, H., et al. (2017). Influence of application method on surface free-energy and bond strenght of universal adhesive systems to enamel. European Journal of Oral Sciences, 125, 385-395.

Knorr, S. D., Combe, E. C., Wolff, L. F., \& Hodges, J. S. (2005). The surface free energy of dental gold-based materials. Dental Materials, 21, 272-277.

Kulaev, I. S., Vagabov, V. M., \& Kulakovskaya, T. V. (2005). The biochemistry of inorganic polyphosphates (2th ed.). West Sussex: John Wiley \& Sons.

Neumann, A. W., Good, R. J., Hope, C. J., \& Seipal, M. (1974). Equation of state to determine surface tensions of low energy solids from contact angles. Journal of Colloid and Interface Science, 49, 291-304.

O'Brien, W. J. (2002). Dental materials and their selection (3th ed.). Chicago: Quintessence Publishing Co.

Olsson, J., van der Heijde, Y., \& Holmberg, K. (1992). Plaque formation in vivo and bacterial attachment in vitro on permanently hydrophobic and hydrophilic surfaces. Caries Research, 26, 428-433.

Owens, D. K., \& Wendt, R. C. (1969). Estimation of the surface free energy of polymers. Journal of Applied Polymer Science, 13, 1741-1747.

Quirynen, M., \& Bollen, C. M. L. (1995). The influence of surface roughness and surfacefree energy on supra-and subgengival plaque formation in man: A review of the literature. Journal of Clinical Periodontology, 22, 1-14.

Rüterman, S., Trellenkamp, T., Bergmann, N., Raab, W. H. M., Ritter, H., \& Janda, R. (2011). A new approach to influence contact angle and surface free energy of resinbased dental restorative materials. Acta Biomaterialia, 7, 1160-1165.

Sipahi, C., Anil, N., \& Bayramli, E. (2001). The effect of acquired salivary pellicle on the surface free energy and wettability of different denture base materials. Journal of Dentistry, 29, 197-204.

Tiveron, A. E., Delbem, A. C., Gaban, G., Sassaki, K. T., \& Pedrini, D. (2013). Effect of resin composites with sodium trimethaphosphate with or without fluoride on hardness, ion release and enamel desmineralization. American Journal of Dentistry, 26, 201-206.

Tsujimoto, A., Barkmeier, W. W., Takamizawa, T., Watanabe, H., Johnson, W. W., Latta, M. A., et al. (2016). Influence of duration of phosphoric acid pre-etching on bond durability of universal adhesives and surface free-energy characteristics of enamel. European Journal of Oral Sciences, 124, 377-386.

Vandiver, D., Dean, D., Patel, N., Bonfield, W., \& Ortiz, C. (2005). Nanoscale variation in surface charge of synthetic hydroxyapatite detected by chemically and spatially specific high resolution force spectroscopy. Biomaterials, 26, 271-283.

van der Mei, H. C., White, D. J., Kamminga-Rasker, H. J., Knight, J., Baig, A. A., Smit, J., et al. (2002). Influence of dentifrices and dietary components in saliva on wettability of pellicle-coated enamel in vitro and in vivo. European Journal of Oral Sciences, 110, 434-438.

van der Mei, H. C., White, D. J., \& Busscher, H. J. (2004). On the wettability of soft tissues in the human oral cavity. Archives of Oral Biology, 49, 671-673.

van Oss, C. J. (1993). Acid-base interfacial interactions in aqueous media. Colloids and Surfaces A: Physicochemical and Engineering Aspects, 78, 1-49.

van Oss, C. J. (1995). Hydrophobicity of biosurfaces - origin, quantitative determination and interaction energies. Colloids Surface B: Biointerfaces, 5, 91-110.

Vogel, G. L., Chow, L. C., \& Brow, W. L. (1983). A microanalitical procedure for the determination of calcium: Phosphate and fluoride in enamel biopsy samples. Caries Research, 17, 23-31.

Vogler, E. A. (1998). Structure and reactivity of water at biomaterial surfaces. Advances in Colloid and Interface Science, 74, 69-117. 